\title{
INVESTIGATING EFL SYRIAN UNDERGRADUATES' VOCABULARY SIZE
}

\author{
Maisaa Moustafa Daaboul and Vahid Nimehchisalem \\ Universiti Putra Malaysia
}

\begin{abstract}
Vocabulary knowledge is an important aspect of learning English as a second/foreign language (ESL/EFL). Previous research has given much attention to ESL/EFL learners' knowledge of vocabulary by measuring their vocabulary size. Yet, in the EFL Syrian context, there is a rarity of research on learners' vocabulary size. Therefore, the present study attempted to investigate vocabulary knowledge of English among EFL Syrian learners by measuring their vocabulary size based on a vocabulary size test (VST) adopted from Nation (2006). The study was conducted among 100 Syrian university learners joining English in one private university in Syria. The data collected from the participating students in the form of numerical responses to the vocabulary test was analyzed using descriptive statistics. The results revealed that the Syrian university learners' overall vocabulary size in English was moderate $(M=5.30)$. Moreover, the scores of the learners across the fourteen 1000-word families/lists of the vocabulary test varied from high to moderate. Based on the results, the study suggested that the average EFL Syrian undergraduates need to expand their vocabulary knowledge through training and instruction on vocabulary-raising awareness. KEYWORDS: VOCABULARY KNOWLEDGE, VOCABULARY SIZE, EFL SYRIAN LEARNERS,
UNDERGRADUATES
\end{abstract}

\section{Introduction}

Knowledge of vocabulary is an important aspect of learning any language. It plays an important role in the success of learning English as a second/foreign language (EFL). Gallo-Crail and Zerwekh (2002) argued that vocabulary is more important than grammar as the lack of vocabulary brings about a breakdown in communication. Similarly, Lightbrown and Spada (2006) pointed out that the importance of vocabulary for EFL learners is highly recognized in the process of communication. While learners can convey their messages in English even if their pronunciation of words and grammar are not accurate, they may not be able to do so if they do not use or lack accurate vocabulary. Mastery and production of a language essentially depend on learners' knowledge of vocabulary in that given language. Therefore, for EFL learners to comprehend the language they listen to or read and produce it, they need to have a good command of vocabulary in English (Teng, 2014).

Research on vocabulary learning has embarked its investigation on learners' vocabulary size. In the ESL acquisition and EFL learning processes, learners' vocabulary size plays a crucial role in advancing their language acquisition and learning because it underlies learners' knowledge of vocabulary, their language learning achievement and development of language proficiency (Laufer, 1997; Nation, 1999; Saville-Troike, 1984; Schmitt, 2000; Waring, 2002). Most of these researchers emphasized the importance of learners' acquisition of 2,000 words as a vocabulary size that is sufficient for their basic use of the language, while they need to have a number of 3,000 to 5,000 for efficiently comprehending reading texts. However, to become more proficient learners of English, university learners need to acquire 10,000 words. They also indicate that learners' smaller vocabulary size is one of the barriers for their language learning. Although previous studies highlighted the importance of learners' knowledge of vocabulary in EFL learning by investigating their vocabulary size, vocabulary learning in the EFL Arab context, including Syria is neglected as classroom teaching and learning still place an emphasis on the four language skills. Moreover, like any other Arab EFL learners, Syrian EFL learners, as stated by Rabab ah (2002), most often lack the necessary and accurate vocabulary when they are involved in English-speaking and writing situations. Consequently, this limited vocabulary makes them unable to freely and accurately express their thoughts or ideas. Therefore, 


\section{INVESTIGATING EFL SYRIAN UNDERGRADUATES' VOCABULARY SIZE}

the current study aimed to determine the EFL Syrian university learners' knowledge of English vocabulary through their vocabulary size.

\section{Literature review}

Learners' knowledge of vocabulary in ESL/EFL learning and development has been extensively researched and investigated by scholars and researchers. One way of investigating learners' knowledge of ESL/EFL vocabulary is measuring or determining their vocabulary size. This is because vocabulary size is relevant to learners' success and proficiency in language learning as well as to academic achievement (Saville-Troike, 1984; Laufer, 1997). It also enables teachers to evaluate learners' development in reading and listening (receptive) as well as in speaking and wiring (productive) in English. According to Webb (2008), learners' vocabulary size is indicative of their productive knowledge or productive skills in English. Many scholars and researchers, in measuring ESL/EFL learners' vocabulary size, have attempted to answer the question regarding the number of words that a learner should know or learn. For instance, Nation (1990) reported that almost $87 \%$ of the words in the text were found to be in the most frequent 2,000 base words of English. Moreover, $13 \%$ of the words were identified as the university words, including academic words, technical words and low-frequency words. It was concluded that all language learners, in order for them to use the language effectively, should know almost 2,000 to 3,000 words. As recommended by McCarthy and O'Dell (1999), learners need to have at least1000-2000 words which enable them to speak and write English normally. Similarly, as emphasized by Laufer (1997), a 3,000 word-level is a threshold vocabulary size that is necessary for reading and comprehending a given text. However, learners having vocabulary size below this level did not do well on their reading tests though their academic ability was somehow high. This is because the 3,000 word-level enables learners to understand or comprehend between $90 \%$ and $95 \%$ of any reading text. However, others pointed out that it is important for a language learner in order to progress in reading and academic texts to have knowledge of at least 5,000 words (Hirsh \& Nation, 1992).

On the other hand, some other researchers believe that learners are required to have at least 2000 words (Nation, 2005). In line with this, a 2000 word-level is the most significant figure or vocabulary size for EFL learners since it enables them to understand almost $80 \%$ of a given reading text. However, if a learner seeks for better development of English, he/she should know 5,000 words (Schmitt, 2000). Moreover, for university proficient learners, they should know 10,000 words (Allen, 1983). As emphasized by Nation (2001), a large vocabulary size is useful for learners of diverse proficiency levels. Therefore, it was concluded that EFL learners should acquire a large vocabulary size to become more proficient in English. As stated by Subon (2013), research indicated that learners' vocabulary size of 10,000 words will enable them to understand almost $93 \%$ of a reading text. Therefore, 10,000 words are suggested as the ideal figure for proficient language learners. Moreover, it is only when learners understand around $98-99 \%$ of a reading text that they will be able to successfully guess meaning of new words from the context. Otherwise, successful guessing of meaning from the context without referring to a dictionary will be complex for them (Waring, 2003).

There are some recent empirical studies which have attempted to measure learners' vocabulary size. According to Kalajahi and Pourshahian (2012), the scores of vocabulary tests of EFL learners suggest that the learners' vocabulary size was adequate only at the levels of 2000 words and 3000 words in addition to their average command of academic vocabulary. On the other hand, the results of the tests indicated that the learners' vocabulary size at the 5000 word-level and the 10,000 word-level was inadequate. Thus, the results suggest that the EFL learners had a somewhat average vocabulary size. Hashemian's and Mostaghasi's (2013) study reported almost similar results to those results reported by Kalajahi and Pourshahian (2012) which indicate that learners' vocabulary size was sufficient at the 2000 word-level and the 3000 word-level and was moderate overall. However, the only difference between these two studies is that learners' vocabulary size reported to be inadequate at the 5000 word-level in Kalajahi's and Pourshahian's (2012) study was found to be an average vocabulary size in Hashemian's and Mostaghasi's (2013). Concerning their vocabulary size at the 10,000 word-level, the result reported by Hashemianand Mostaghasi (2013) supported Kalajahi's and Pourshahian's (2012) result as the learners had an inadequate vocabulary size at this level of words. This corroborates the need emphasized by Nation (1990) that learners have to know almost 20003000 words for basic ESL/EFL learning. 


\section{INVESTIGATING EFL SYRIAN UNDERGRADUATES' VOCABULARY SIZE}

There is another test for measuring learners' vocabulary size named Vocabulary Size Test (VST). The VST was developed from Nation (2006). It comprises $(\mathrm{n}=14)$ 1,000 word-families or lists, and each list has 10 items so there are $(n=140)$ items. The test was developed based on the assumption of the gradual difficulty order of its lists. In other words, while the first list is regarded as the least difficult list, the fourteenth list is regarded the most difficult one. The VST test was also used by a few previous studies. As reported by Karami (2012), the entire VST was made by Iranian EFL examinees. Yet, in Beglar's (2010) study, only part of the VST was made by the examinees. While the beginners answered only the first four 1000-word-families of the VST, the intermediate learners answered only the first eight 1000 word-families. In addition, in Karami's (2012) study, it was found that the EFL learners scored highly only in the first two 1000 word-lists of the VST. However, Nguyen and Nation (2011) reported that the learners scored highly in the first four 1000 word-lists of the VST. Studies also showed that the examinees' scores or vocabulary size normally decreased or dropped as they moved towards the less familiar levels of the VST. While the first 1000 word-level was the easiest level, the fourteenth 1000 word-level was the most difficult (Beglar, 2010; Karami, 2012; Nguyen \& Nation, 2011).

Thus, although these studies measured learners' vocabulary size through various tests, Laufer et al. (2004) revealed that one of the important assumptions underlying these different tests of learners' vocabulary size is that the frequency level of words known by learners is a good indicator of their vocabulary development. For the question regarding the number of words that a learner should know in ESL/EFL learning, it can be concluded that the 2000 word-level is a good number for efficient basic language use. However, for effective comprehension of reading texts, learners should acquire a vocabulary size of 3,000 to 5,000. For a higher proficiency of English, 10,000 words can be the best vocabulary size, especially for those university learners. Some of the above studies (Hashemian\&Mostaghasi, 2013; Kafipour et al., 2011; Kalajahi\&Pourshahian, 2012; Subon, 2013) investigating learners' vocabulary size through various tests have not clearly reported how much time the students were given for performing the vocabulary test.

In this regard, Karami (2012) reported that a practical vocabulary test should require about 45 minutes to be completed by learners. Finally, although the findings of these last few studies seem contradicting (Beglar, 2010; Karami, 2012; Nguyen \& Nation, 2011) these studies indicated that the VST is a valid instrument for measuring learners' vocabulary size. Hence, it can be also used for learners of different levels of English proficiency. Another more recent study by Yunu et al. (2017) investigated the vocabulary size of university learners majoring in English and coming from both Malaysia and Thailand. The investigation of vocabulary size in this study was based on the test developed by Nation and Beglar (2007) on learners' receptive vocabulary knowledge. The results of the study indicated that the Malaysian university students scored a higher VST than the Thai university students. This higher VST scored the Malaysian university students as interpreted by the researchers was due to the emphasis of the Malaysian government through its language policies on improving learners' knowledge in English. Another reason behind this higher VST scores could be the higher degree of exposure to English in real life communicative situations in the Malaysian context. In other words, while the Malaysian learners come from an ESL context where they are exposed to English in their daily life situations, the Thai university students come from an EFL context where they are rarely exposed to English. Such exposure assists learners in acquiring sufficient knowledge in vocabulary in English. Therefore, such results provide insights into pedagogical and instructional strategies for enhancing EFL learners' vocabulary, including integration of an academic course that is exclusive to vocabulary in English and equipment of university lecturers or instructors with advanced vocabulary instructional methods for teaching English to university learners.

\section{Methodology}

\section{Research Design}

The present study used a quantitative research design, which suits the nature and purpose of the study. Specifically, the quantitative research design adopted in the present study falls within descriptive research designs. In descriptive studies, the researcher attempts to measure the participants' vocabulary size and describes it as it is without any attempt to change it. 


\section{INVESTIGATING EFL SYRIAN UNDERGRADUATES' VOCABULARY SIZE}

\section{Study Setting and Participants}

The present study was carried out one private university located in a rural area of the large city of DeirAtiyah An-Nabek District of Rif Dimashq Governorate, the Republic of Syria. This university was chosen as the study setting it is one of the officially accredited higher educational institutions in Syria. Moreover, due to its location, accessing the participants for collecting the necessary data was possible.

The focus of the present study was on first year university learners of English joining this university $(\mathrm{n}=400)$. In using a simple random sampling technique that is based on the researcher's assumed knowledge of the target population (Gelo, Braakmann, \&Benetka, 2008; Marshall, 1996) the target population of the study was assigned into umbers from 1 to 400 with the instructor's assistance. This was followed by random selection of the sample ( $\mathrm{n}=100$ students). Their age ranged from 19 years old to 23 years old. The males represented $(\mathrm{n}=50)$, and the females accounted for $(\mathrm{n}=50)$.

\section{Research Instrument}

The data collection instrument used in this study was the VST which was adopted from Nation (2006). The VST is considered a scale for measuring learners' receptive knowledge of vocabulary in English. The test was first reported and developed by Nation (2006) from the British National Corpus (BNC) (available at http://www.victoria.ac.nz/lals/staff/paul-nation/nation.aspx). The VST consists of 14 word-families or lists, and each family/list consists of 10 items so overall, there are 140 items. The 14 lists are also assumed to be ordered from the most familiar ones to the least familiar ones. In other words, they follow a normal order of difficulty; that is, from the least difficult to the most difficult (Nation \&Beglar, 2007; Nation \&Coxhead, 2014). The following example taken from the test is a sample item of the VST:

Soldier: He is a soldier. Soldier: He is a soldier.

a. person in a business

b. student

c. person who uses metal

d. person in the army

The current study used the VST as a measure of the Syrian EFL learners' vocabulary size for two important reasons. First, several previous studies provided evidence supporting the validity of the test (e.g., Karami, 2012; Nation \&Beglar, 2007; Nation \& Coxhead, 2014). Moreover, these studies reported that the test is suitable for testing the vocabulary size of learners with different levels of English proficiency.

\section{Data Collection and Analysis}

Prior to the procedure of data collection, an oral approval had been obtained from the president of the university. Then, the instructor was contacted by the researcher for permission to carry out the study. After this, the participating learners were asked for approval of the research participation consent. Then, they were instructed on the VST and its objectives. Some examples were also provided on how to do the test. Most of the instructions were in Arabic in order to make them clear for the participants. The participants also set for the test and completed it in the classroom. It took between 50 to 60 minutes to finish the test.

For the data analysis, first, the researcher imported the participants' responses to the VST into SPSS program (Version 19.0). After inputting the data in the form of numerical responses to the VST, the process of data analysis began. The analysis of the learners' vocabulary size performed was exclusive to descriptive statistics including the minimum, maximum, mean values and standard deviations. This was applied to the participants' overall vocabulary size as well as their vocabulary size of each family of the fourteen 1000word family levels in the VST. 


\section{Results and Discussion}

The present study also focused on measuring the Syrian EFL learners' vocabulary size. The study adopted a vocabulary test from Nation (2006), known as the VST. The scores of the Syrian EFL learners were also analyzed using a descriptive analysis or descriptive statistics. The mean values: the overall value and the values of each 1000-word family- list/level ( $\mathrm{n}=14$ word family-lists) were calculated. Table (1) presents the results obtained from the descriptive analysis of the learners' scores in the VST.

Table 1: Descriptive Statistics of the learners' vocabulary size

\begin{tabular}{|c|c|c|c|c|c|}
\hline 1000-Word Family/ List & Min & Max & Mean & SD & $\begin{array}{l}\text { Order of } \\
\text { Difficulty }\end{array}$ \\
\hline First & 2 & 10 & 8.49 & 1.70 & 1 \\
\hline Second & 1 & 10 & 7.20 & 2.36 & 2 \\
\hline Third & 1 & 10 & 7.03 & 2.24 & 3 \\
\hline Fourth & 0 & 10 & 7.00 & 2.15 & 4 \\
\hline Fifth & 0 & 10 & 5.04 & 2.05 & 7 \\
\hline Sixth & 0 & 10 & 4.79 & 2.06 & 11 \\
\hline Seventh & 1 & 10 & 5.41 & 2.23 & 5 \\
\hline Eighth & 0 & 10 & 5.10 & 2.35 & 6 \\
\hline Ninth & 0 & 10 & 5.02 & 2.45 & 9 \\
\hline Tenth & 0 & 10 & 5.03 & 2.21 & 8 \\
\hline Eleventh & 0 & 10 & 4.95 & 2.22 & 10 \\
\hline Twelfth & 0 & 9 & 3.81 & 2.41 & 12 \\
\hline Thirteenth & 0 & 8 & 3.77 & 1.93 & 13 \\
\hline Fourteenth & 0 & 6 & 1.69 & 1.46 & 14 \\
\hline Overall & 1.45 & 4.68 & 5.30 & .86 & \\
\hline
\end{tabular}

KEY: Mean values 0-3.99 (low), 4-6.99 (moderate), 7-10 (high)

The above table concerning the results of the VST of the learners shows that the participants' overall performance on the 14 word family-levels is by no means good or adequate because the mean value falls in the moderate range. This is because the overall mean value $(\mathrm{M}=5.30)$. The learners' scores of the 14 word family levels were also analyzed in terms of their mean values. As shown above, the mean values vary from high to low. Specifically, the learners' vocabulary size at the first and second word-family levels was high because the mean values for both levels $(\mathrm{M}=8.49 \& 7.20)$ fall in the high range of (7-10). This is followed by the participants' vocabulary size in the third and fourth word family lists or levels as they scored high mean values ( $\mathrm{M}=7.03 \& 7.00)$. This could be due to the learners' familiarity of the words in these four levels of the VST.

The above results also demonstrate that the Syrian learners' performance in the VST in the other seven word family levels (from the 5 th to the 11 th levels) was moderate or medium. They scored moderate mean values $(\mathrm{M}=5.04,4.79,5.41,5.10,5.02,5.03 \& 4.95)$ in the 5th, 6th, 7th, 8th, 9th, 10th and 11th levels, respectively. These values fall in the moderate or medium range of (4-6.99). Hence, such results underlying the learners' moderate vocabulary size in these seven word family levels of the VST indicate that the learners could have found these words in the seven levels more difficult than those in the four earlier levels. This also suggests that the learners did not seem to be familiar with the words in these seven levels of the VST. 


\section{INVESTIGATING EFL SYRIAN UNDERGRADUATES' VOCABULARY SIZE}

For the three remaining 1000 word- levels (from the 12th to the 14th), the results of the present study show that the Syrian learners' vocabulary size was low or weak. Looking at the mean values scored in these last three levels, they are $(M=3.81)$ for the twelfth level, $(M=3.77)$ for the thirteenth level and $(M=1.69)$ for the fourteenth level. All these mean values fall in the low range (0-3.99). Such results indicate that the words listed in these last three levels of the VST seem to be the most difficult words for the learners.

The mean values of the 14 word-family levels were put in order in the form of a serial number that start with number 1 for the highest mean value which indicates that this level was the easiest or most familiar and ends with number 14 standing for the list that is most difficult or least familiar. From the above table, it can be seen the order of difficulty is normal for the first four levels (first, second, third and fourth). However, the order of difficulty starts deviating from the assumed normal order of difficulty from the fifth level to the eleventh level. For instance, the fifth level becomes the 7th order, while the seventh level becomes the 5th order, and the sixth level becomes the 11th order, whereas the eleventh level becomes the 10th order. In other words, from these two examples of the lack of normal order of difficulty imply that the fifth level did not appear to be easier than the seventh level as it was assumed by the designer of the VST since the order of difficulty of these two levels proved that the fifth level appeared to be more difficult than the seventh level. This could be due to the existence of words like deficit, compost, fracture and bacterium in the fifth 1000 word-level that the Syrian learners did not seem to be familiar with. However, looking at the words existing in the seventh 1000 word-level, there are words like olive, shudder, yoghurt and quilt which seem to be more familiar especially for learners to come across in most commonly used reading text books. These words made the fifth 1000 word-level appear more difficult than the seventh 1000 word-level.

Finally, the order of difficulty became normal again for the last three 1000 word-levels (from 12th to the 14th level). In other words, from the mean values of these three 1000-word families, we can see that the mean value of the 12th 1000 -word family was $(\mathrm{M}=3.81)$, and then, this value got lower when moving to the 13th and the 14th 1000-word families ( $M=3.77 \& 1.69$, respectively). This means that the three families were the most difficult ones in the VST. It also suggests that the words available in these three levels were the most challenging words for the Syrian learners. As the learners moved towards these three families, they may have encountered words, which were not familiar to them.

In this study, the learners' vocabulary size was also measured in each level of the fourteen 1000 word-levels of the VST. The results indicated that the learners' vocabulary size of the fourteen 1000 word-levels varied from high in the first four levels (from the 1st to the 4th level) to medium in the other seven levels (from the 5 th to the 11th level) and to low in the last three levels (from the 12th to the 14th level). First, such results indicated that the learners could sit for the entire test rather than answering only some levels of it. This was also reported by Karami (2012) who found that Iranian EFL examinees took the whole VST. However, this contradicts what was found by Beglar (2010) as the examinees did not take the entire VST. The beginners took only the first four 1000 word-levels, while the intermediate learners took only the first eight 1000 wordlevels.

Comparing the above results of the Syrian learners' vocabulary size in each of the fourteen 1000 word-levels of the VST to those reported in previous studies using the same vocabulary test, the results resemble those results of Karami (2012). However, the only exception is that while the vocabulary size of the Syrian learners was high in the first four 1000 word-levels, in Karami's (2012) study, the learners scored highly in the first two 1000 word-levels. The results of the present study also support those results reported by Nguyen and Nation (2011). Yet, these researchers pointed out at the learners' high vocabulary size in the first two 1000 word-levels. Other studies using different vocabulary size tests (Hashemian \& Mostaghasi, 2013; Ibrahim et al., 2013; Kalajahi \& Pourshahian, 2012; Kırmız1, 2014) showed that the learners' vocabulary size was good or even high, but this was exclusive to certain word levels such as 2000 word-level.

In determining the order of difficulty of the fourteen 1000 word-levels of the VST, the current study shows interesting results. In designing this test, it was assumed that the items of the VST at the different levels would form a difficulty continuum from easy to difficult (Beglar, 2010; Nation, 2006; Read, 2000). This suggests that the examinees' scores or vocabulary size should normally decrease or drop as they move towards the less frequent levels. For this, it appears that the first 1000 word-level was the easiest level and the fourteen 1000 word-level was the most difficult, which was also found by a few several studies (Beglar, 2010; Karami, 2012; Nguyen\& Nation, 2011). Yet, the results of the current study indicate that this 


\section{INVESTIGATING EFL SYRIAN UNDERGRADUATES' VOCABULARY SIZE}

assumption of the order of difficulty is not totally true as it was found that from the 5th 1000 word-level to the 11th 1000 word-level. This resembles results reported by Karami (2012) and Nguyen and Nation (2011) as they found that the order of difficulty of some 1000 word-levels of the VST goes against this assumption. The researchers attributed this to the existence of some English loan words in some of the 1000 word-levels such as those in the 11th word-level which made it easier than other levels preceding it. Other factors affecting that could be the background of the participants and their levels of proficiency in English.

\section{Implications and Conclusion}

The results of the present study have several significant implications for educators, EFL instructors and researchers. In making vocabulary learning training successful, instructors should explain to their students why they have to acquire a larger number of vocabulary, what role vocabulary plays in language learning and what learners can benefit from acquiring vocabulary. They can also engage learners in group discussions and activities where learners share their knowledge of vocabulary and expand their vocabulary size. By so doing, learners can be motivated to be active and independent language learners. In other words, the ultimate aim of such vocabulary learning training should be promoting learners' autonomy in language learning. EFL lecturers/ instructors should also know their students' vocabulary knowledge through their vocabulary size that can be achieved using various tests. This is important because without knowing their students' vocabulary size, it may turn out to be difficult for instructors to advice and guide their students on how to increase their knowledge of vocabulary (Nation, 2011).

Although the current study obtained important results of the Syrian EFL learners' vocabulary size, there are several limitations that should be addressed along with useful recommendations for future research. First, the participants in this study are $(\mathrm{n}=100)$ Syrian EFL learners joining English in one private university in Syria, which may affect our results. Therefore, future researchers should interpret such results carefully. Moreover, future studies may look at the vocabulary size of a larger number of students so that results obtained can be generalized. This study investigated the vocabulary size of the Syrian students without considering the variances in terms of age, gender and levels of English proficiency. However, in order to enrich our understanding of EFL learners' vocabulary size, future research should look at the variances of vocabulary size among learners according to these three variables. Consideration of these variables when investigating vocabulary size will allow EFL instructors to better understand individual learners' knowledge of vocabulary in English. As a result, instructors will be able to design teaching materials and use various teaching methods that meet the individual differences in learners' needs for vocabulary in English.

\section{References}

Allen, F. A. (1983). Techniques in teaching vocabulary. New York: Oxford University Press.

Beglar, D (2010) A Rasch-based validation of the Vocabulary Size Test. Language Testing 27(1), 101-18.

Catalan, R. M. J. (2003). Sex differences in L2 vocabulary learning strategies. International Journal of Applied Linguistics, 13(1), 54-77.

Chamot, A. U., \& O'Malley, J. M. (1994). The CALLA handbook: Implementing the cognitive academic language learning approach. Reading, MA: Addison-Wesley Publishing Company.

Gallo-Crail, R., \&Zerwekh, R. (2002). Language learning and the Internet: Student strategies in vocabulary acquisition. New technologies and language learning: Cases in the less commonly taught

languages, 55-79. 


\section{INVESTIGATING EFL SYRIAN UNDERGRADUATES' VOCABULARY SIZE}

Gelo, O., Braakmann, D., \&Benetka, G. (2008). Quantitative and qualitative research: Beyond the debate. Integrative psychological and behavioral science, 42(3), 266-290.

Hashemian, M., \&Mostaghasi, H. (2013). The Relationship between L2 Learners' Vocabulary Learning Strategies and Lexicon Size. A Paper Presented at the First National Conference on Teaching English, Literature, and Translation, Kharazmi - Safashahr International Institute for Research and Education, Shiraz, Iran.

Hirsh, D. \& Nation, P. (1992). What vocabulary size is needed to read unsimplified texts for pleasure? Reading in a Foreign Language, 8(2), 689-696.

Ibrahim, E. H. E., Othman, K., Sarudin, I., \& Muhamad, A. J. (2013). Measuring the Vocabulary Size of Muslim Pre-University Students. World Applied Sciences Journal, 21(21), 44-49.

Kafipour, R., Yazdi, M., Soori, A., \&Shokrpour, N. (2011). Vocabulary levels and vocabulary learning strategies of Iranian undergraduate students. Studies in Literature and Language, 3(3), 64-71.

Kalajahi, S. A. R., \&Pourshahian, B. (2012). Vocabulary learning strategies and vocabulary size of ELT students at EMU in Northern Cyprus. English Language Teaching, 5(4), 138-149.

Karami, H. (2012). The development and validation of a bilingual version of the Vocabulary Size Test. RELC Journal, 43(1), 53-67.

Laufer, B. (1997). The lexical plight in second language reading: Words you don't know, words you think you know, and words you can't guess. In Second Language Vocabulary Acquisition (eds J. Coady\& T. Huckin), pp.2-34. Cambridge University Press, New York.

Laufer, B., Elder, C., Hill, K., \& Congdon, P. (2004). Size and strength: do we need both to measure vocabulary knowledge? Language testing, 21(2), 202-226.

Marshall, M. N. (1996). Sampling for qualitative research. Family practice, 13(6), 522- 526.

McCarthy, M., O’Dell, F., \& Shaw, E. (2001). Basic vocabulary in use. Cambridge: Cambridge University Press.

Nation, P. (1999). Learning vocabulary in another language. English Language Institute Occasional Publication 19. Victoria University Wellington, New Zealand.

Nation, I. S. (2001). Learning vocabulary in another language. Ernst KlettSprachen.

Nation, I. (2006). How large a vocabulary is needed for reading and listening? Canadian Modern Language Review, 63(1), 59-82.

Nation, I.S., \&Beglar, D. (2007). A vocabulary size test. The Language Teacher, 31(7): 9-13.

Nation, P., \& Coxhead, A. (2014). Vocabulary size research at Victoria University of Wellington, New Zealand. Language Teaching, 47(03), 398-403.

Nguyen, L., T., C., \& Nation, I.S. (2011). A bilingual vocabulary size test of English for Vietnamese 


\section{INVESTIGATING EFL SYRIAN UNDERGRADUATES' VOCABULARY SIZE}

learners. RELC Journal 42(1),86-99.

Read, J. (2000).Assessing Vocabulary. Cambridge: Cambridge University Press.

Saville-Troike, M. (1984). What really matters in second language learning for academic achievement?TESOL quarterly, 199-219.

Schmitt, N. (2000). Vocabulary in language teaching. Ernst KlettSprachen.

Teng, F. (2014). Research into practice: Strategies for teaching and learning vocabulary. Beyond Words, 2(2), 41-57.

Waring, R. (2003). At what rate do learners learn and retain new vocabulary from reading a graded reader? Reading in a Foreign language, 15(2), 130.

Webb, S. (2008). Receptive and productive vocabulary sizes of L2 learners. Studies in Second language acquisition,30(01),79-95.

Yunus, K., Mohamad, M., \& Waelateh, B. (2016). The breadth of receptive vocabulary knowledge among English major university students. Journal of Nusantara Studies (JONUS), 1(1), 7-17.

\section{Contact details of authors}

Maisaa Moustafa Daaboul

Faculty of Modern Languages and Communication,

Universiti Putra Malaysia 43400 Serdang,

Selangor Darul Ehsan,Malaysia

Email: maisadaaboul80@gmail.com

Vahid Nimehchisalem

Faculty of Modern Languages and Communication,

Universiti Putra Malaysia 43400 Serdang,

Selangor Darul Ehsan,Malaysia

Email:vahid@upm.edu.my,nimechie@gmail.com

\section{Biodata}

Maisaa Moustafa Daaboul is a postgraduate student at the Faculty of Modern Languages and Communication, Universiti Putra Malaysia. She obtained her Bachelor's Degree in English from Damascus University in 2000. She accomplished her Master in Applied Linguistics in 2017 at Universiti Putra Malaysia.

Vahid Nimehchisalem holds a PhD in Teaching English as a Second Language. He is a Senior Lecturer in the Faculty of Modern Languages and Communication, Universiti Putra Malaysia. His main research area is assessing ESL writing, but he has published on a variety of topics from English language teachers' professional development to vocabulary learning strategies. He is chief editor of the International Journal of Education and Literacy Studies. 